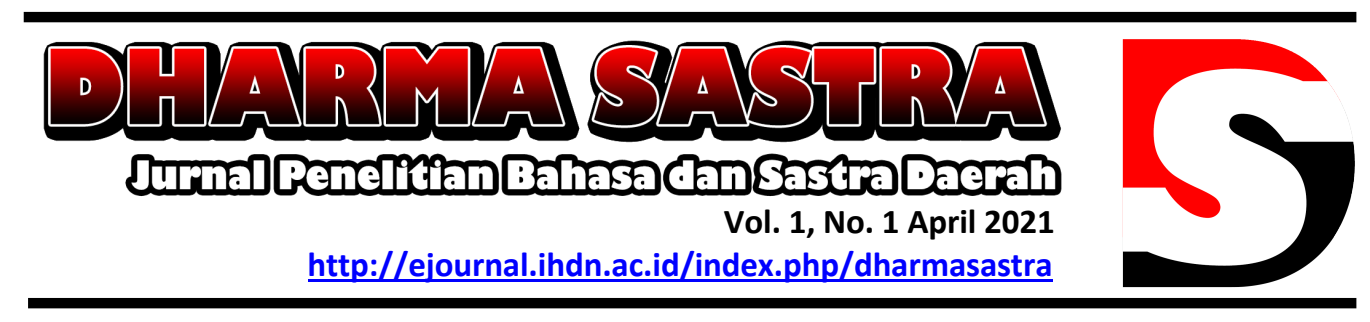

\title{
Mantra Pengasihan Tungtung Tangis Perspektif Bentuk Fungsi dan Makna
}

\author{
Pande Gede Brahmandika
}

UHN IGB Sugriwa Denpasar, Email : pandegede383@gmail.com

\begin{tabular}{l}
\hline \multicolumn{1}{c}{ Info Artikel } \\
\hline Diterima : 27 Maret 2021 \\
Direvisi : 31 Maret 2021 \\
Diterbitkan : 2 April 2021 \\
Keywords: \\
Qualitative, Structural \\
Functional, Meaning, \\
Mantra Tungtung Tangis. \\
\end{tabular}

\begin{abstract}
The purpose of this study was to describe the form, function and meaning of the pangasihan tungtung tangis mantra. This research uses functional structural theory and meaning theory. The method used is a qualitative method. The instruments used in this study were interviews, observations, in-depth literature study of the informants. Determination of informants using purposive sampling technique. The results of this study are: first, the tungtung tangis mantra as a subtle form of pangasihan is used to attract one's opponent to sympathy. In its development, the tungtung tangis mantra can be used as a chuckle or buntilan or gegemet (provision) to obtain someone's desire to be fulfilled. Second, the form of shading the target so that it is precisely the sasran to the recipient of the pangasihan tungtung tangis mantra.
\end{abstract}

\section{Pendahuluan}

Tatkala manusia untuk pertama kali mulai menyadari bahwa kepercayaanya melalui mitos primitifnya itu sia-sia, bahwa alam tidak bisa dibujuk bukan karena enggan memenuhi permintaan manusia, melainkan karena tidak mampu memahami bahasa manusia dan kesadaran itu tentunya menimbulkan goncangan jiwa. Peristiwa ini mengharuskan manusia menghadapi masalah baru yang merupakan titik balik dan krisis dalam hidup intelektual maupun hidup moralnya. Sejak itu manusia menemukan dirinya dicekam kesendirian yang mendalam, rentan terhadap kesepian mendalam yang membawa manusia untuk merenungkan dunia sekitarnya, dalam pengertian inilah sejarah manusia mulai sadar melihat hubungan bahasa dengan realitas dari sudut yang berbeda (Kaelan, 2009:21).

Fungsi mantra memang tidak aktif, kecuali sebagai penggerak konsentrasi pikiran untuk menuju ke satu tujuan, yaitu : menaklukan suksma, jiwa dan pikiran orang lain yang menjadi sasarannya, atau menolak maksud jahat dari lawan. Ketajaman dan kekuatan magis (gaib) itu sendirilah yang timbul, sesuai dengan tujuan yang sudah diniatkan sejak semula. Mantra hanya menjadi pedoman dalam mempersatukan pikiran, andai kalimat atau kata-kata mantra itu diubah satu atau dua kata, tentu tidak akan mempengaruhi asalkan yang menjalankan sudah berkeyakinan penuh dan tau betul tujuan mantra tersebut. Seperti di dalam ajaran Kanda Pat Bali, satu mantra permohonan bisa diubah dan berkembang menjadi mantra- 
mantra yang lain, misalnya menjadi mantra penolak, mantra pengesengan, mantra pelarisan, mantra pangasihan (Yendra, 2012:3).

Mantra sebenarnya hampir sama dengan pengertian sugesti, tetapi mantra terikat oleh bentuk, susunan kalimat, kata-kata yang tidak boleh diubah, sebagai warisan dari para ahli gaib di jaman dulu, walaupun mantra dan sugesti memiliki perbedaan, namun ia tetap memiliki persamaan bahwa keduanya difungsikan untuk mempengaruhi orang, karena itu mantra dan sugesti juga bisa bekerja sama. Sugesti sifatnya luwes dan luas, serta dapat disesuaikan pada keadaan tempat dan waktu (Yendra, 2012:41). Definisi secara umum mantra adalah sejumlah aksara tertentu, atau sebuah pola gabungan kata-kata Sansekerta yang diambilkan dari kitab suci weda, sebagai symbol bunyi. Aksara penyusun mantra berfungsi sebagai lambang dari bunyi yang dikehendaki, agar menghasilkan efek maka mantra harus dibunyikan atau dilafalkan dengan cara yang tepat sesuai dengan ritme (swara) dan bunyi warna tertentu.

Arti atau makna kata-kata dalam sebuah mantra sudah terkandung di dalam swarupa atau perwujudannya sendiri dari kata tersebut, perwujudannya berupa lambang kemahakuasaan, kekuatan atau kesaktian dari Hyang Widhi, yang dimanifestasikan dalam wujud dewa, dewi, betara, betari, Sang Hyang atau unsur panca mahabutha (Nala, 2006:164,165). Dalam bahasa sansekerta kata mantra adalah sangat bermakna karena kata tidak memiliki sinonim dalam bahasa lain, maka mantra adalah suatu kata atau sekumpulan kata-kata tertentu yang jika diucapkan berulang-ulang dengan sugesti diri atau sugesti dari luar diri akan mendatangkan suatu kekuatan gaib sesuai dengan makna mantra yang diucapkan. Mantra juga merupakan perwujudan pikiran yang merepresentasikan kekuatan kosmik,yang menggunakan pengaruh mereka dengan getaran suara. Ada dua hal yang penting dalam sebuah mantra pertama mantra harus bermakna, yaitu dalam pengertian umum harus mengandung arti yang tepat, di dalam sihir bali ini setiap mantra bisa memiliki dua arti yaitu arti sekala dan arti niskala.

Setiap mantra yang diyakini untuk digunakan harus dibuat "Hidup" terlebih dahulu jika tanpa dibuat hidup atau dibangkitkan terlebih dahulu maka mantra tidak akan berarti apaapa. Kedua, adalah mantra harus dibuat "hidup" agar mantra menjadi hidup maka dalam praktek penghayatannya harus dilakukan dengan sungguh-sungguh dalam suatu proses "Laku" yang terus menerus tanpa kenal putus, bila sudah demikian barulah energy mantra akan dirasakan kehadirannya dan rasakan hasilnya (Yendra, 2012:65). Sama halnya dengan Pangasihan Tungtung Tangis memiliki daya magis tersendiri yang tergolong dalam mantra yang halus, masuk dalam kategori white magic, Sesuai dengan tujuan white magic yang meyakini hanya untuk kebaikan, serta difungsikan sebagai pengikat lawan jenis. Mantra Tungtung Tangis juga tergolong dalam mantra ajian, rajah, pelet dan pangasihan. Bahasa yang digunakan dalam mantra Tungtung Tangis adalah Bahasa Kawi dilafalkan pelan-pelan dan juga dalam batin.

Mantra tungtung tangis identik dengan dukun, paranormal atau di bali disebut Balian, istilah dukun tidak hanya dikenal dikalangan daerah tertentu saja melainkan di seluruh Indonesia sehingga beranekaragam kekayaan tentang ilmu pedukunan yang dimiliki di Indonesia. Kalau di Bali dukun disebut balian, kata balian berasal dari kata wali yang artinya kembali. Dari kata wali lalu menjadi kata walian atau balian yang artinya orang yang dapat mengembalikan kondisi tubuh seseorang seperti dalam keadaan sebelum sakit, sehingga masyarakat sangat percaya dengan keberadaan balian di tengah-tengah masyarakat. Balian merupakan suatu fenomenan keberagaman masyarakat animistic dan dinamistik yang masih mewarnai umat Hindu Bali, ini tidak hanya terlihat pada masyarakat tradisional melainkan 
mulai tampak dalam masyarakat modern. Ketika peran daya nalar manusia sudah mulai tidak bisa memenuhi keinginan, ketajaman akal sudah mulai tumpul dalam memecahkan masalah, ketika rasio sudah tidak bisa memuaskan keinginan jasmani dan rohani, maka kecendrungan untuk mendapatkannya hanya ada di dunia magis dengan menemui balian. Manusia yang terimbas bau modern kini justru cenderung mengagumi dunia klenik, takut salahang Bhatara, Pemastu, yakni tradisi turun temurun yan tunduk di bawah himbauan dunia imajinasi, tentunya sangat jauh dari dunia nalar manusia.

Klasifikasi balian di bali ada tiga jenis yakni balian kapican, balian ketakson, balian usada (Nala, 2006:96). Balian Kapican adalah balian atau dukun yang mendapatkan keahliannya karena memperoleh suatu pica, sesuatu yang bertuah dan berkhasiat. Pica ini dapat berwujud batu permata, lempengan logam, keris, cinci, kalung, tulang serta benda lainya. Balian Ketakson (tetakson) adalah balian atau dukun yang mendapatkan keahlian karena kemasukan taksu, roh atau kekuatan gaib yang member kecerdasan, mukjizat ke dalam dirinya. Kedua jenis balian ini, baik Balian Kapican maupun Ketakson, untuk menjadi pengobat tidaklah perlu melalui suatu proses belajar atau berguru seperti balian usada. Mereka telah dikodratkan (kalinggihan) oleh Hyang Kuasa untuk menjadi pengobat. Sedangkan Balian Usada adalah para dukun yang mendapatkan keahliannya karena belajar atau melalui suatu proses yang disebut aguru waktera.

Keunggulan dari mantra pangasihan tungtung tangis supaya dicintai orang, wijaksara triaksara dapat pula dimanfaatkan. Cara ini disebut memasang pangeger atau guna-guna. Caranya adalah mendatangi seorang balian mengutarakan keluh kesah agar bisa dibantu oleh balian tersebut, maka jro balian akan mengirim guna-guna dengan cara mengubah letak wijaksara Triaksara. Wijaksara Ang diletakan pada dasar mata (bagian belakang bola mata), Ung di lengkungan mata (korneo mata, bagian depan bola mata), dan Mang di tengah- tengah bola mata. Jadi, posisi wijaksara Ung pada paling depan dari bola mata, disusul oleh Mang ditengah, dan paling belakang adalah Ang. Urutannya dari depan ke belakang adalah UngMangAng (Nala, 2006:129). Dengan adanya wijaksara triaksara yang diberikan dari jro balian maka sudah bisa dipastikan pangasihan tersebut bisa digunakan melalui sorotan mata dapat dikirim wijaksara sesuai keinginan si pengerim mantra tungtung tangis. Pandangan mata tetap diarahkan ke orang yang dituju, wijaksara triaksara yang telah dikirim ini ditarik kembali melalui hidung, setelah masuk di bawa kedalam hrdaya atau jantung. Dengan cara ini diharapkan orang yang dituju akan jatuh cinta atau tetap mencintai, mengasihi kepada orang yang mengirim wijaksara tersebut.

Pangasihan tuntung tangis sebenarnya bersifat netral. Pangasihan menjadi bermanfaat disaat digunakan untuk tujuan mulia, seperti misalnya merekatkan kembali keluarga yang telah retak atau menolong orang yang terkena ilmu pengasih, Ibarat seorang dokter harus mengobati suatu penyakit, maka dokter tersebut harus mengetahui seluk-beluk penyakit agar penyakit tersebut bisa diatasi. Hanya saja ilmu ini akan menjadi masalah jika digunakan untuk niat jahat. Tetapi yakinlah, hukum karma tetap berjalan. Siapapun yang menggunakan ilmu pengasih untuk tujuan jahat akan menemukan karma yang setimpal. Pasangan yang didapat dengan cara pangasihan tidak akan bertahan lama, mereka akan dipisahkan oleh kesusahan hidup ataupun kematian.

Dengan kehadiran teknologi generasi millennial cendrung meninggalkan nilai-nilai budaya dan agama, mengejar nilai-nilai kebebasan, hedonisme, party dan pergaulan bebas. Ternyata apabila ditelusuri, bahwa generasi millennial tersebut banyak yang berdampak negatif pada dirinya sendiri juga. Dengan gaya hidup teknologi, nilai-nilai yang ditanamkan pada diri seorang anak akan hilang mengikuti arus generasi millennial. Generasi millennial 
cendrung bersikap individualis yang mementingkan diri sendiri tanpa memikirkan orang lain. Generasi millennial berpengaruh terhadap kehidupan sosial, yang lebih mementingkan ego masing-masing sehingga sikap dan prilaku yang terjadi adalah menyimpang melakukan sesuatu sesuai dengan keinginan sendiri tanpa memikirkan sekitar. Dalam masyarakat memang telah terjadi pergeseran kepercayaan terhadap ilmu magis, ilmu sihir $_{2}$ dan sejenisnya. Dimana ilmu-ilmu seperti itu dianggap tahayul, kuno, ketinggalan jaman. Hal itu terjadi kemungkinan akibat semakin jarang orang yang mampu menjadi pakar ilmu seperti itu, dan yang lebih menyedihkan ilmu magis disalahgunakan oleh oknum-oknum tak bertanggungjawab. Akibatnya ilmu magis tidak lagi mau diturunkan sembarangan oleh ahlinya atau seorang Maha Guru, takut disalah gunakan, sehingga lama-kelamaan ilmu magis akan hilang.

Hal ini membuat peneliti tertarik untuk melakukan kajian terhadap mantra pangasihan tungtung tangis sebagai objek kajian. Kajian mantra pengasihan tungtung tangis ini diharapkan mampu untuk mengubah pola pikir masyarakat agar dapat melestarikan tradisi serta warisanwarisan leluhur berupa mantra-mantra pangasihan tungtung tangis yang telah mulai ditinggalkan.

\section{Metode}

Metode penelitian adalah metode yang dipergunakan dalam kegiatan mengadakan penelitian dalam berbagai bidang ilmu pengetahuan (Netra, 1974:1). Metode kualitatif memberikan perhatian terhadap data alamiah, data dalam hubunganya dengan konteks keberadaanya (Ratna, 2007:47). Cara-cara inilah mendorong metode kualitatif dianggap sebagai multimetode sebab penelitian pada gilirannya melibatkan sejumlah besar gejala sosial yang relevan. Dalam ilmu sosial sumber datanya adalah masyarakat, data penelitiannya adalah tindakan-tindakan sedangkan dalam ilmu sastra sumber datanya adalah karya, naskah, data penelitiannya sebagai data formal adalah kata-kata kalimat dan wacana. Jenis penelitian yang digunakan dalam penelitian ini adalah kualitatif deskriptif dengan pendekatan studi etnografi. Pada penelitian ini juga menggunakan unit analisis yang dimaksud masyarakat yang akan memberikan informasinya kepada peneliti. Sedangkan objek penelitian yang akan dianalisis berupa mantra Tungtung Tangis, sehingga nantinya peneliti dapat menganalisa simbolisme mantra terhadap bentuk, funsi serta makna.

\section{Pembahasan}

Pengertian Mantra sebenarnya hampir sama dengan pengertian sugesti, tetapi mantra terikat oleh bentuk, susunan kalimat, kata-kata yang tidak boleh diubah, sebagai warisan dari para ahli gaib di jaman dulu. Menurut definisi umum, mantra diambil dari kata dalam bahasa sansekerta, yaitu "mantra" atau "manir", yang merujuk pada kata-kata dalam kitab suci umat Hindu, Veda. Mantra juga tidak sama maknanya dengan doa, doa merupakan permohonan kepada tuhan. Sementara, mantra itu ibarat upaya untuk menarik picu senapan yang bernama daya hidup.

Daya kehidupan manusia menjadi factor adanya aura magis (gelombang elektromagnetik) yang melingkupi badan manusia. Aura magis memiliki sifatnya masingmasing dikarenakan adanya perbedaan esensi dari unsur-unsur yang membangun jasad manusia. Unsur-unsur tersebut berasal dari bumi, langit, cahaya, dan teja yang keadaanya selalu dinamis sepanjang masa. Aura magis dalam diri manusia dengan aura alam semesta terdapat kaitan erat, yakni adanya gelombang energi saling mempengaruhi secara kosmismagis. Dinamika energi yang saling mempengaruhi mempunyai dua kemungkinan, pertama 
bersifat saling berkaitan secara kohesif dan menyatu (sinergi) dalam wadah keharmonisan, kedua bersifat tolak-menolak (adesif). Laku sesirih (meredam segala nafsu) dan semadi (olah bathin) merupakan sebuah upaya harmonisasi dengan cara menyinergikan aura magis mikrokosmos dalam kehidupan manusia (inner world) dengan aura alam semesta makrokosmos, agar tercipta suatu hubungan transenden yang harmonis dalam dimensi vertical (antara manusia dengan tuhan) serta dimensi horizontal (antara manusia sebagai jagad kecil dengan jagad besar alam semesta).

Mantra adalah teknologi kuno. Mantra bukanlah doa, namun merupakan sejenis senjata atau alat berwujud kata-kata atau kalimat sebagai teknologi spiritual tingkat tinggi hasil karya leluhur nusantara di masa silam. Mantra dibuat melalui tahapan spiritual yang tidak mudah. Mantra hanya dapat digunakan untuk keperluan tertentu, misalnya menaklukan musuh di medan perang, atau diperuntukan sebagai alat medis penyembuhan. Mantra bebas digunakan untuk acara dan keperluan apa saja tergantung si pemakai. Namun setiap penyalahgunaan mantra pasti memiliki konsekuensi yang berat berupa karma atau hukuman Tuhan yang dirasakan langsung maupun kelak setelah ajal.

Walaupun mantra dan sugesti memiliki perbedaan, namun ia tetap memiliki persamaan bahwa keduanya difungsikan untuk mempengaruhi orang, karena itu mantra dan sugesti juga bisa bekerja sama. Sugesti sifatnya luwes dan luas, serta dapat disesuaikan pada keadaan tempat dan waktu (Yendra dalam Sihir Bali, 2012:41). Dalam bahasa sansekerta kata mantra adalah sangat bermakna karena kata tidak memiliki sinonim dalam bahasa lain, maka mantra adalah suatu kata atau sekumpulan kata-kata tertentu yang jika diucapkan berulang-ulang dengan sugesti diri atau sugesti dari luar diri akan mendatangkan suatu kekuatan gaib sesuai dengan makna mantra yang diucapkan. Mantra juga merupakan perwujudan pikiran yang merepresentasikan kekuatan kosmik,yang menggunakan pengaruh mereka dengan getaran suara. Ada dua hal yang penting dalam sebuah mantra pertama mantra harus bermakna, yaitu dalam pengertian umum harus mengandung arti yang tepat, di dalam sihir bali ini setiap mantra bisa memiliki dua arti yaitu arti sekala dan arti niskala. Setiap mantra yang diyakini untuk digunakan harus dibuat "Hidup" terlebih dahulu jika tanpa dibuat hidup atau dibangkitkan terlebih dahulu maka mantra tidak akan berarti apa-apa. Kedua, adalah mantra harus dibuat "hidup" agar mantra menjadi hidup maka dalam praktek penghayatannya harus dilakukan dengan sungguh-sungguh

dalam suatu proses "Laku" yang terus menerus tanpa kenal putus, bila sudah demikian barulah energy mantra akan dirasakan kehadirannya dan rasakan hasilnya. Sama halnya dengan Mantra yang digunakan untuk memikat wanita sebagai berikut : Pangasihan Tungtung Tangis memiliki daya magis tersendiri yang tergolong dalam mantra yang halus, masuk dalam kategori white magic, Sesuai dengan tujuan white magic yang meyakini hanya untuk kebaikan, serta difungsikan sebagai pengikat lawan jenis. Mantra Tungtung Tangis juga tergolong dalam mantra ajian, rajah, pelet dan pengasihan. Bahasa yang digunakan dalam mantra Tungtung Tangis adalah Bahasa Kawi dilafalkan pelan-pelan dan juga dalam batin

Kaki hyang nini hyang kembulane

Siulam kapicut hati, maripet nangis

Tan delu-delu, maring asih maring aku

Apan pengasih tungtung tangisku, angrasuk

Ring atmane si......tan pasha si.....apan kakerik

Kerik kikile, kerik kerik limpane, kerik kerik

Tungtungan jiwane si......tan las maring aku

Sida sida kaki hyang nini hyang engone, sing nyapatin, 
Nangis si.....edan si.....maring aku

Pomo, pomo, pomo.

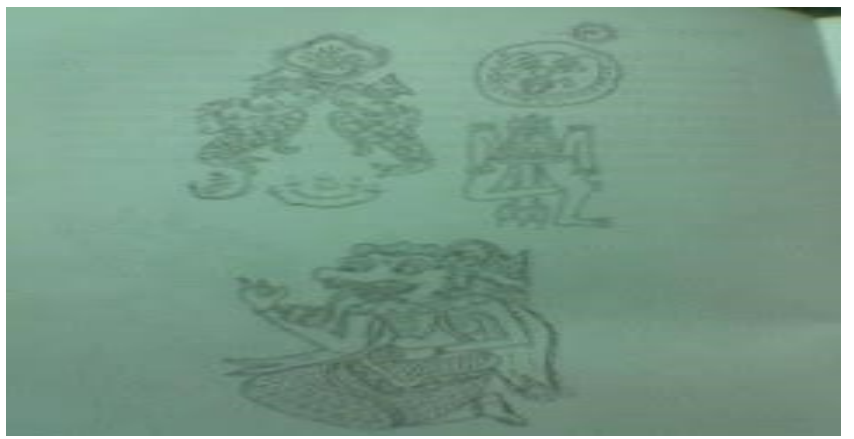

Gambar 1 : Rerajahan guna-guna tungtung tangis

Rerajahan berasal rajah. Rajah bermakna suratan atau gambar yang mengandung kekuatan gaib atau magis religious. Rerajahan adalah salah satu sarana dalam proses pengobatan berbentuk lukisan atau gambar yang mengandung kekuatan gaib atau magis religius. Lukisan ini dikombinasikan dengan aksara bali biasa (Wreastra dan swalalita), maupun aksara suci (wijaksara/bijaksara dan modre) ditulis di atas suatu media. Rerajahan dipergunakan sebagai sarana pengobatan (tamba, kuratif) ataupun pencegahan (pekakas, tumbal, preventif) penyakit atau marabahaya. Rerajahan yang biasa digunakan oleh balia sebagai berikut : (1) Benda Langit, seperti matahari, bulan dan bintang, (2) Tumbuhtumbuhan, terutama bunga padma, teratai, (3) Binatang, seperti burung, ikan harimau, naga, ular, monyet, (4) Bhuta Kala, Raksasa, makhluk yang seram, (5) Binatang berkepala manusia, Bhuta, raksasa, atau dewa (Ngurah Nala, 2011:175).

Rajah pengasihan atau dalam bahasa balinya sering disebut dengan rerajahan pengasihasih, rerajahan ini selain mempunyai pungsi pokok untuk pengasihan ada pungsi lain yang terkandung didalamnya, karena dalam satu rajah pengasihan ada yang memiliki dua pungsi, tiga pungsi sampai lima pungsi yang berbeda-beda. Pengasihan atau pemikat yang media rajahnya adalah badan kita sendiri, rajah pengasihan tergolong ampuh karena memakai keputusan sang hyang samara tantra, dan mendapat restu dari sang hyang samara tantra, pemakai dari rajah pemikat ini akan di kasihi dari semua kalangan yang difokuskan kepada wanita. Ada beberapa titik yang di rajah pemikat tungtung tangis ini yaitu : wuntuniya ( Gigi ), layah ( Lidah ), telapan lima ( telapak tangan ), awakniya ( badan ) selain di rajah di badan, rajah tungtung tangis yang di rajah di badan juga harus di buatkan buntilan (sesuatu rajah yang dibungkus, karena dalam rajah itu ada sebuah mantra yang ditunjukan kepada target tertentu selain itu juga bisa untuk semua orang atau sakewenang).

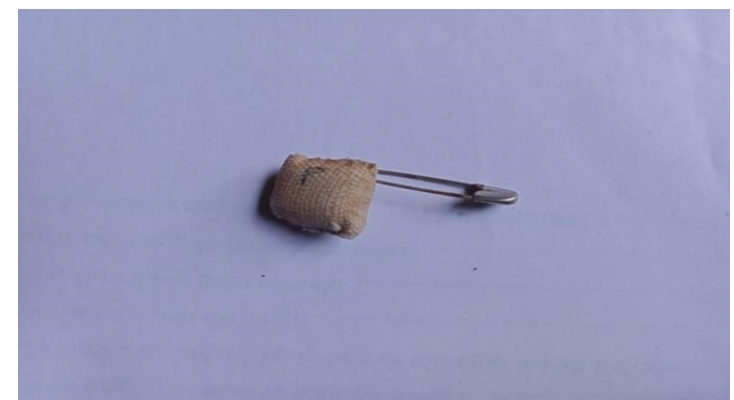

Gambar 2 : Buntilan atau Jimat Pengasihan (Gegemet) 
Jimat pengasihan atau cekelan adalah suatu benda atau kekuatan yang dipelihara oleh manusia untuk suatu maksud dan tujuan tertentu. Pantangan dari jimat pengasihan ini adalah tidak diperbolehkan ke toilet, setra/kuburan dan tempat-tempat dianggap leteh (kotor) (Wawancara, Jro Mk Pande Ketut Badung).

\section{Kesimpulan}

Hasil penelaah mantra pangasihan ialah bahwa secara teks, mantra Pangasihan Tungtung Tangis memiliki daya magis tersendiri yang tergolong dalam mantra yang halus, masuk dalam kategori white magic, Sesuai dengan tujuan white magic yang meyakini hanya untuk kebaikan, serta difungsikan sebagai pengikat lawan jenis. Mantra Tungtung Tangis juga tergolong dalam mantra ajian, rajah, pelet dan pengasihan. Bahasa yang digunakan dalam mantra Tungtung Tangis adalah Bahasa Kawi dilafalkan pelan-pelan dan juga dalam batin.

Dinamika energi yang saling mempengaruhi mempunyai dua kemungkinan, pertama bersifat saling berkaitan secara kohesif dan menyatu (sinergi) dalam wadah keharmonisan, kedua bersifat tolak-menolak (adesif). Laku sesirih (meredam segala nafsu) dan semadi (olah bathin) merupakan sebuah upaya harmonisasi dengan cara menyinergikan aura magis mikrokosmos dalam kehidupan manusia (inner world) dengan aura alam semesta makrokosmos, agar tercipta suatu hubungan transenden yang harmonis dalam dimensi vertical (antara manusia dengan tuhan) serta dimensi horizontal (antara manusia sebagai jagad kecil dengan jagad besar alam semesta).

\section{Daftar Pustaka}

Anggono, Toha. 2007. Metode Penelitian. Jakarta: Universitas Terbuka.

Alex, Sobur. (2004). Semiotika Komunikasi.Bandung: Rosda Karya.Budiardjo.

Abimanyu, Petir. (2014). Mistik Kejawen. Jogjakarta : Palapa

H.Hoed, Benny. (2008). Semiotik \& Dinamika Sosial Budaya: Depok, Komunitas Bambu

Miriam. (1991). Aneka Pemikiran Tentang Kuasa dan Wibawa.Jakarta: Pustaka Sinar Harapan. M.S Kaelan. (2009). Filsafat Bahasa Semiotika dan Hermeneutika. Jogjakarta: Paradigma Moleong, L. 2001. Metodologi penelitian kualitatif. Bandung: PT: Remaja Rosdakarya. 